CLINICAL STUDY

\title{
Grapefruit juice and licorice increase cortisol availability in patients with Addison's disease
}

\author{
Paal Methlie ${ }^{1,2}$, Eystein E S Husebye ${ }^{1,3}$, Steinar Hustad ${ }^{1}$, Ernst A Lien ${ }^{1,2}$ and Kristian Løvås ${ }^{1,3}$ \\ ${ }^{1}$ Institute of Medicine, University of Bergen, 5021 Bergen, Norway and ${ }^{2}$ The Hormone Laboratory and ${ }^{3}$ Department of Medicine, Haukeland University \\ Hospital, 5021 Bergen, Norway \\ (Correspondence should be addressed to P Methlie at Institute of Medicine, University of Bergen; Email: paal.methlie@med.uib.no)
}

\begin{abstract}
Objective: Failure to mirror the diurnal cortisol profile could contribute to the impaired subjective health status in Addison's disease (AD). Some patients report benefit from the use of various nutritional compounds. The objective of this study was to investigate the impact of licorice and grapefruit juice (GFJ) on the absorption and metabolism of cortisone acetate (CA).

Design: Patients $(n=17)$ with AD on stable CA replacement therapy were recruited from the outpatient clinic at Haukeland University Hospital, Norway. They were assessed on their ordinary CA medication and following two 3-day periods of co-administration of licorice or GFJ.

Methods: Time series of glucocorticoids (GCs) in serum and saliva were obtained, and GCs in 24 h urine samples were determined. The main outcome measure was the area under the curve (AUC) for serum cortisol in the first $2.6 \mathrm{~h}$ after orally administered CA.

Results: Compared with the ordinary treatment, the median AUC for serum cortisol increased with licorice (53 783 vs $50882, P<0.05$ ) and GFJ (60 661 vs $50882, P<0.05$ ). Median cortisol levels in serum were also elevated $2.6 \mathrm{~h}$ after tablet ingestion (licorice $223 \mathrm{vs} 186 \mathrm{nmol} / \mathrm{l}, P<0.05$; GFJ $337 \mathrm{vs}$ $186 \mathrm{nmol} / \mathrm{l}, \mathrm{P}<0.01)$. Licorice increased the median urinary cortisol/cortisone ratio (0.43 vs 0.21 , $P<0.00001$ ), whereas GFJ increased the (allo-tetrahydrocortisol + tetrahydrocortisol)/tetrahydrocortisone ratio $(0.55$ vs $0.43, P<0.05)$.

Conclusion: Licorice and in particular GFJ increased cortisol available to tissues in the hours following oral CA administration. Both patients and physicians should be aware of these interactions.
\end{abstract}

European Journal of Endocrinology 165 761-769

\section{Introduction}

Patients with Addison's disease (AD) have impaired subjective health (1) and increased all-cause mortality (2). Standard practice is lifelong replacement of glucocorticoid (GC) and mineralocorticoid hormones. Most patients with $\mathrm{AD}$ receive $15-25 \mathrm{mg}$ oral hydrocortisone $(\mathrm{HC})$ or $25-37.5 \mathrm{mg}$ cortisone acetate (CA) two or three times a day (3). Physiological cortisol secretion exhibits a distinct circadian pattern with levels rising steeply prior to wakening and declining to low levels in the evening. Conventional treatment imperfectly mimics this diurnal variation and renders the patient both over-treated and under-treated during the $24 \mathrm{~h}$ cycle (4). It is possible that the failure to mirror the physiological rhythm of cortisol could contribute to the impaired quality of life in AD. Longterm over-treatment with GC hormones poses an increased risk of osteoporosis (5) and may be associated with higher cardiovascular morbidity $(6,7)$.

Different modes of GC administration have been proposed to optimize the replacement therapy, including multi-dosage (8), weight-adjusted dosage regimens (9), and continuous s.c. HC infusions (10). Recent studies show that novel delayed-release and sustained-release formulations of $\mathrm{HC}$ provide more physiological serum cortisol patterns $(11,12)$. However, the pharmacokinetics of GCs most likely depends on various environmental factors such as diet and gut microflora, which may interact with pharmacogenetic variation. Examples of such factors emerge from anecdotal observations of patients with adrenal insufficiency who benefit from the use of various nutritional compounds such as licorice and grapefruit juice (GFJ) (13-16).

The main active ingredients in licorice are glycyrrhetinic acid and its metabolite glycyrrhizic acid, which are potent inhibitors of $11 \beta$-hydroxysteroid dehydrogenase $(11 \beta-H S D)$ type 1 and type $2(17,18)$. These isoenzymes play key roles in the metabolism of cortisol (19). 11ß-HSD type 1 is located mainly in liver, adipose tissue, and muscle, where its principal function is reduction of cortisone to cortisol. Hence, circulating cortisone serves as a depot that can be readily activated to cortisol in the tissues (20). Increased activity of 
$11 \beta$-HSD type 1 has been proposed to be involved in the pathogenesis of obesity, the metabolic syndrome, polycystic ovary syndrome, hypertension, and osteoporosis. 11ß-HSD type 2 oxidizes cortisol to cortisone in vivo and is abundantly expressed in the kidneys. Here, this enzyme prevents illicit activation of the mineralocorticoid receptor by inactivation of cortisol. Impaired function of 11ß-HSD type 2, for example, by inhibition with glycyrrhetinic acid or due to rare genetic 11 $\beta$-HSD type 2 deficiencies (apparent mineralocorticoid excess), is a well-recognized mechanism of pseudohyperaldosteronism. While the effects of $11 \beta$-HSD type 1 and 2 inhibition are well described in healthy subjects, there are no systematic studies on the impact of licorice consumption in $\mathrm{AD}$ patients on replacement therapy.

GFJ contains numerous bioactive ingredients, but their influence on the absorption and metabolism of CA (or HC) is not clear. Previous reports show that flavonoid glycosides and furanocoumarins present in GFJ impact many intestinal and hepatic enzymes $(21,22)$ and that GFJ can increase the bioavailability of several compounds by inhibition of cytochrome P450 subsystems (2B1, 2B4, 2B6, 3A4, and 3A5). CYP3A4 converts cortisol to $6 \beta$-hydroxycortisol, which is readily excreted in the urine. Cortisol, along with other GCs and some common drugs, are known inducers of CYP3A4 (23), which at least in some subject could increase cortisol clearance. In fact, there are case reports of acute cortisol insufficiency in patients with AD on CYP3A4 inducing anti-epileptic drugs (24). Additionally, GFJ may interfere with the P-glycoprotein, which normally redirects xenobiotics and steroid compounds from the enterocytes back to the intestinal lumen (21). There are also reports of GFJ having inhibitory effects on 11 $\beta$-HSD $(25,26)$.

The aim of this exploratory study was to determine to what extent ingestion of licorice and GFJ influences the absorption and metabolism of CA. We therefore investigated whether 3-days of co-administration of each of these compounds with CA altered the pharmacokinetics of cortisol and cortisone in serum, saliva, and urine in 17 patients with $\mathrm{AD}$ on stable $\mathrm{CA}$ replacement therapy.

\section{Subjects and methods}

\section{Subjects}

Seventeen subjects were recruited from the outpatient clinic at Haukeland University Hospital (Table 1). The $\mathrm{AD}$ diagnosis was previously confirmed by the presence of hypocortisolism, increased ACTH levels, and positive 21-hydroxylase antibodies. To be included in the study, the participants had to be on stable CA therapy. Exclusion criteria were systolic blood pressure (BP) above $150 \mathrm{mmHg}$ or diastolic BP above $90 \mathrm{mmHg}$, habitual use of GFJ or licorice, current use of other GCs,

Table 1 Subject characteristics.

\begin{tabular}{|c|c|c|c|c|c|c|c|c|c|c|}
\hline \multirow[b]{2}{*}{ Subject } & \multirow[b]{2}{*}{ Gender } & \multirow{2}{*}{$\begin{array}{c}\text { Age } \\
\text { (years) }\end{array}$} & \multirow[b]{2}{*}{ BMI } & \multirow[b]{2}{*}{ BP } & \multicolumn{3}{|c|}{ CA (mg/dose) } & \multirow[b]{2}{*}{ FC } & \multirow{2}{*}{$\begin{array}{l}\text { Concomitant } \\
\text { diseases }\end{array}$} & \multirow{2}{*}{$\begin{array}{l}\text { Other } \\
\text { medications }\end{array}$} \\
\hline & & & & & Morning & Midday & Evening & & & \\
\hline 1 & $\mathrm{~F}$ & 50 & 29.7 & $110 / 70$ & 10.0 & 10.0 & 10.0 & 0.10 & APS1, renal calcinosis & \\
\hline 2 & $\mathrm{~F}$ & 75 & 24.9 & $127 / 62$ & 12.5 & 6.3 & 6.3 & 0.10 & $\begin{array}{l}\text { Hypothyroidism, } \\
\text { pernicious anemia }\end{array}$ & $\begin{array}{l}\text { Thyroxine, B12-inj, } \\
\text { calcium }\end{array}$ \\
\hline 3 & $\mathrm{~F}$ & 56 & 20.7 & $117 / 80$ & 25.0 & 12.5 & 12.5 & 0.15 & Hypothyroidism & Thyroxine \\
\hline 4 & $M$ & 38 & 25.6 & $140 / 87$ & 25.0 & & 12.5 & 0.10 & Hypothyroidism & Thyroxine \\
\hline 5 & $\mathrm{~F}$ & 53 & 20.9 & $114 / 72$ & 12.5 & & 12.5 & 0.10 & $\begin{array}{l}\text { Osteoporosis, } \\
\text { depression }\end{array}$ & $\begin{array}{l}\text { Alendronate, } \\
\text { venlafaxine, HRT }\end{array}$ \\
\hline 6 & $\mathrm{~F}$ & 67 & 27.9 & $115 / 80$ & 12.5 & 12.5 & 12.5 & 0.10 & Osteoporosis & Calcium \\
\hline 7 & $\mathrm{~F}$ & 51 & 25.5 & $98 / 58$ & 12.5 & & 12.5 & 0.10 & & \\
\hline 8 & M & 58 & 26.0 & $134 / 85$ & 10.0 & 10.0 & 5.0 & 0.05 & Podagra & $\begin{array}{l}\text { Simvastatin, } \\
\text { Allopurinol }\end{array}$ \\
\hline 9 & $\mathrm{~F}$ & 39 & 36.0 & $114 / 76$ & 12.5 & 12.5 & 12.5 & 0.08 & & \\
\hline 10 & $\mathrm{~F}$ & 52 & 26.2 & $113 / 79$ & 12.5 & & 12.5 & 0.20 & & \\
\hline 11 & $\mathrm{~F}$ & 73 & 31.2 & $139 / 87$ & 25.0 & & 12.5 & 0.10 & $\begin{array}{l}\text { Celiac disease, } \\
\text { fibromyalgia, asthma }\end{array}$ & Montelukast \\
\hline 12 & $\mathrm{~F}$ & 32 & 22.1 & $127 / 85$ & 25.0 & 12.5 & & 0.10 & & \\
\hline 13 & $\mathrm{M}$ & 34 & 25.1 & $128 / 76$ & 25.0 & & 12.5 & 0.10 & Diabetes mellitus type 1 & Insulin \\
\hline 14 & $\mathrm{~F}$ & 31 & 33.8 & $140 / 83$ & 15.0 & 10.0 & 10.0 & 0.10 & Asthma, hypothyroidism & $\begin{array}{l}\text { Desloratadine, } \\
\text { thyroxine }\end{array}$ \\
\hline 15 & M & 44 & 25.3 & $121 / 79$ & 25.0 & & 12.5 & 0.10 & & \\
\hline 16 & M & 44 & 24.0 & $119 / 66$ & 12.5 & 12.5 & 12.5 & 0.10 & & \\
\hline 17 & $\mathrm{~F}$ & 59 & 24.4 & $121 / 69$ & 25.0 & & 12.5 & 0.14 & Hypothyroidism & Thyroxine \\
\hline
\end{tabular}

$\mathrm{CA}$, cortisone acetate; M, male; F, female; BMI, body mass index $\left(\mathrm{kg} / \mathrm{m}^{2}\right)$; BP, blood pressure systolic/diastolic (mmHg); FC, fludrocortisone (mg/day); APS1, autoimmune polyendocrine syndrome type 1 ; HRT, norethindrone+estradiol. 
pregnancy, major disease or major accident requiring hospitalization during the last 3 months, or malignant disease. In the event of incidental minor disease (i.e. flu), the assessment was postponed for at least 2 weeks after recovery. None of the subjects had known renal or hepatic failure.

\section{Study design}

All participants maintained their regular medication throughout the study (Table 1). The subjects were assessed on three occasions: on standard treatment, on the third day of licorice intake, and on the third day of GFJ use. After the assessment on standard treatment, the subjects were randomized to ingest licorice or GFJ starting 2 days prior to the next examination. Intake of these nutrients was separated by a wash out period of at least 3 weeks. The administration of GFJ and licorice was standardized by oral and written instructions to the subjects. On each occasion, the subjects were asked whether they had complied, and this information was recorded. Licorice $(\sim 25$ tablets) was provided in three bags containing $24 \mathrm{~g}$ Läkerol Dark Premium (Leaf, Sweden) each, and the participants were encouraged to consume one bag of licorice evenly during the day. According to the manufacturer, $24 \mathrm{~g}$ Läkerol Dark Premium is equivalent to $150 \mathrm{mg}$ glycyrrhetinic acid, with no added sugar or salt. The GFJ was Meierienes Premium Rosa Grapefruktjuice (Tine SA, Oslo, Norway) and made from fresh pink grapefruit. No conservatives, sugar, or salts were added in the production process, and the GFJ was not concentrated. The subjects drank $200 \mathrm{ml}$ GFJ three times a day immediately on taking their regular medication.

The study was conducted at the clinical research facility at Haukeland University Hospital and was approved by the regional ethics committee and the Data Inspectorate of Norway. The study was in accordance with the principles of the Declaration of Helsinki and its amendments.

\section{Assessments}

At $0800 \mathrm{~h}$, the subjects met at the clinical research facility after an overnight fast. Weight, height, and BP were measured, and adverse events or subjective discomfort were recorded. The morning dose of CA was taken with a standardized breakfast consisting of two slices of bread, $150 \mathrm{ml}$ coffee or tea, and $200 \mathrm{ml}$ water. During GFJ intervention, water was replaced by GFJ. Intake of licorice was started immediately after breakfast. Blood and saliva were obtained at the time of medication and subsequently every $20 \mathrm{~min}$ for $160 \mathrm{~min}$. Blood was sampled through a permanent i.v. catheter placed in a forearm vein. The catheter was flushed with heparin and isotonic saline water between samples, and the first blood drawn was discarded to avoid dilution. Saliva was obtained by Salivette cotton swabs (Sarstedt, Darmstadt, Germany). 24 h urine was also collected.

\section{Biochemical analysis}

Serum cortisol and cortisone were determined by liquid chromatography mass spectrometry according to Ionita et al. (27). Plasma ACTH was analyzed by a chemiluminescent immunometric assay (Immulite 2000, Siemens AG, Munich, Germany).

Steroids in saliva were extracted by loading $200 \mu \mathrm{l}$ oral fluid diluted with $200 \mu \mathrm{l} \mathrm{H}_{2} \mathrm{O}$ onto a pre-conditioned Oasis MCX $\mu$ Elution solid-phase extraction 96-well plate (Waters Corp., Milford, MA, USA). Washing steps

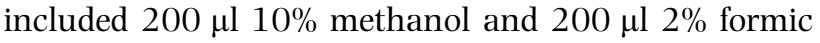
acid before elution with two times acetonitrile (ACN) $50 \mu \mathrm{l}$. The eluate was evaporated, reconstituted, and injected into a Dionex Ultimate $3000 \times 2$ Dual Analytical HPLC system (Sunnyvale, CA, USA) coupled to an Applied Biosystems/MDS SCIEX API 4000 (Carlsbad, CA, USA) equipped with an electrospray ion source (ESI) operating in positive mode. The analytical column, Synergi Fusion C18 $50 \times 2.0 \mathrm{~mm} 2.5 \mu \mathrm{m}$ particle size (Phenomenex, Torrance, CA, USA), was developed by gradient elution (flow $300 \mu \mathrm{l} / \mathrm{min}$ ) from 35 to $100 \%$ methanol from 0.00 to $3.75 \mathrm{~min}$. The MRM transitions 363/121 and 361/161 were used as the quantifier transitions for cortisol and cortisone, respectively, while 363/327 and 361/105 were chosen as qualifier transitions. The internal standard (IS), isotope-labeled cortisol-d4 (97.5 atom \%, CDN Isotopes, Inc., Quebec, Canada), was monitored by transitions $367 / 121$ and $367 / 331$. The between-batch precision ranged from 6.5 to $10.9 \%$ for cortisol and 5.6 to $8.3 \%$ for cortisone. The lower limit of quantification was $0.15 \mathrm{nmol} / \mathrm{l}$ for both steroids.

Twenty-four hour excretion of allo-tetrahydrocortisol (aTHF), tetrahydrocortisol (THF) and tetrahydrocortisone (THE), cortisol and cortisone were measured in urine samples according to previously published methods developed at our laboratory (28). 6 $\beta$-Hydroxycortisol was analyzed by adding $250 \mu \mathrm{l} 0.1 \mathrm{M}$ hydrogen chloride and cortisol-d4 (IS, $20 \mathrm{nmol} / \mathrm{l}$ ) to $500 \mu \mathrm{l}$ urine. The sample was vortex mixed and centrifuged, before subsequent liquid-liquid extraction with $2000 \mu \mathrm{l}$ ethyl acetate and washing with $250 \mu \mathrm{l}$ $0.1 \mathrm{M}$ sodium hydroxide. One thousand microliters of the supernatant were evaporated and reconstituted in $300 \mu \mathrm{l} 15 \% \mathrm{ACN}$. The analytical column, an Agilent Zorbax SBHD C18 $2.1 \times 50 \mathrm{~mm} 1.8 \mu \mathrm{m}$, ran a binary gradient of $\mathrm{H}_{2} \mathrm{O}: \mathrm{ACN}$ with $0.1 \%$ formic acid; $t=0-2.0 \mathrm{~min}$ $20 \%$ ACN; $t=2.0-6.0$ min $20-50 \%$ ACN. Quantifications were based on the following MRM transitions in ESInegative mode; $6 \beta$-hydroxycortisol $423 / 347$ (quantifier) and 423/313 (qualifier), and d4-cortisone 411/335 (quantifier) and $411 / 301$ (qualifier). Assay precision ranged from 3.9 to $4.7 \%$. 


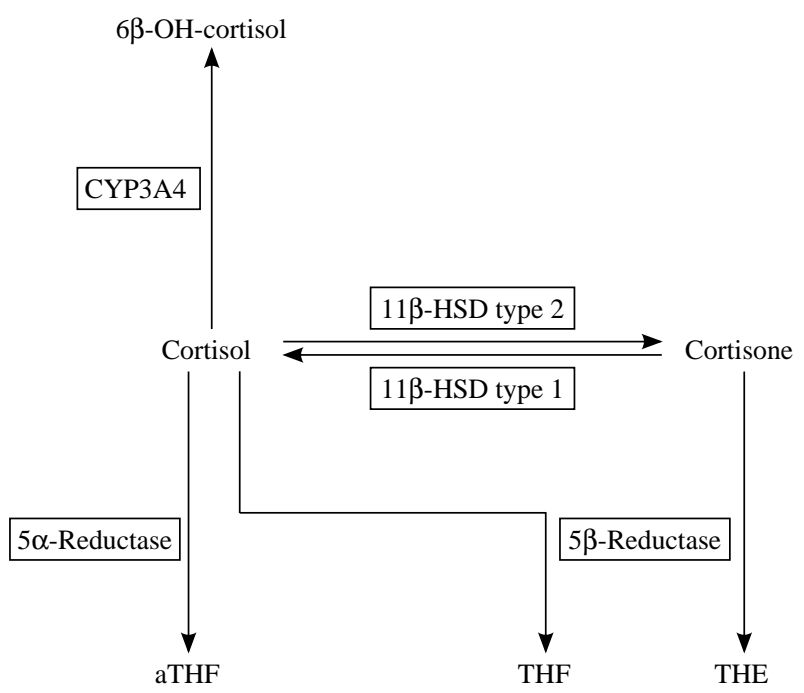

Figure 1 Schematic overview of cortisol metabolism. Cortisone acetate administered orally is converted to cortisol by hepatic $11 \beta$ HSD type 1. Circulating cortisol and cortisone are metabolized mainly by $5 \alpha / \beta$-reductases, but CYP $4503 \mathrm{~A} 4$ may also contribute. $11 \beta$-HSD, $11 \beta$-hydroxysteroid dehydrogenase; CYP3A4, cytochrome P450 3A4; THF, tetrahydrocortisol; aTHF, allo-tetrahydrocortisol; THE, tetrahydrocortisone.

\section{Statistical analysis}

The following pharmacokinetic parameters for cortisol and cortisone were computed from the time series of serum and saliva samples: the area under the curves, AUC (calculated according to the trapezoidal rule, not extrapolated to infinity); the peak concentration, $C_{\max }$; time of maximum concentration, $T_{\max }$; and concentration at the end of profile, $C_{t=160}$. If a set of serum or saliva samples was not complete for an individual, it was not included in the calculation of AUC, $C_{\max }$, and $T_{\max }$. Plasma ACTH obtained at $t=0$ often exceeded the upper limit of quantification $(n=21$ of 51$)$. The procedure for sample dilution was not available in our laboratory, and statistics on these determinations were not performed.

The ratio of urinary cortisol/cortisone was used as a measure of 11ß-HSD type 2 activity, whereas the (aTHF + THF)/THE ratio and the 6 $\beta$-hydroxycortisol/ cortisol ratio were used to assess the activities of $11 \beta$-HSD type 1 and CYP3A4 respectively (Fig. 1).

All measurements are reported as median (range), unless otherwise indicated. For the primary endpoint, AUC cortisol, paired Friedman statistics was used to compare standard treatment, licorice and GFJ co-administration, and post hoc analyses performed by paired Wilcoxon signed rank tests with adjusted $P$ values using the Holm method. Comparisons of all other variables to standard treatment were done using the paired Wilcoxon signed rank tests. Correlation analyses between serum and saliva GC levels were computed by Spearman's rank correlation. Statistical significance was defined as a two-tailed $P<0.05$.

\section{Results}

All the subjects completed the study without adverse effects and reported to have taken licorice and GFJ as instructed. Both licorice and GFJ were well tolerated. Due to difficulties in accessing a peripheral vein, we were unable to obtain a full set of blood samples in two subjects (subjects 7 and 14 after use of licorice and GFJ, respectively), but complete sets of saliva samples were collected from these two subjects. Multiple saliva samples from one subject (subject 1 on standard treatment) were discarded because of insufficient oral fluid recovered for analysis.

Serum and salivary levels of cortisol and cortisone were generally very low at the time of oral CA administration $(t=0)$ but increased within $20 \mathrm{~min}$ in all subjects. The time to peak concentration $\left(T_{\max }\right)$ varied considerably between subjects and whether GFJ was taken with CA. For most subjects, the maximum levels in serum were in the range of 450-550 nmol/l for cortisol and $40-80 \mathrm{nmol} / \mathrm{l}$ for cortisone. Cortisol concentrations decreased much more rapidly than cortisone (Fig. 2). As expected, there were strong overlaps in pharmacokinetic parameters between the treatments, but not in pairwise comparisons, because the patients used different CA doses and dose regimens. The cortisone levels in serum and saliva had not reached baseline levels at $t=160$, which indicate that the differences in AUC between interventions and baseline are underestimated.

Salivary cortisol showed strong correlation to serum levels during standard treatment (Spearman's correlation coefficient, $\rho$ 0.95), use of licorice $(\rho 0.89)$, and GFJ ( $\rho$ 0.91). Salivary cortisone also strongly correlated with serum cortisol during standard treatment ( $\rho 0.83)$, use of licorice ( $\rho 0.78)$, and use of GFJ ( $\rho 0.78)$.

BP was decreased in licorice-ingesting subjects compared with standard treatment: sitting systolic BP: 120 vs $121 \mathrm{mmHg}, \quad P<0.01$; 1-min standing systolic BP: 110 vs $126 \mathrm{mmHg}, P<0.01$; and 1 -min standing diastolic BP: 70 vs $83 \mathrm{mmHg}, P<0.01$.

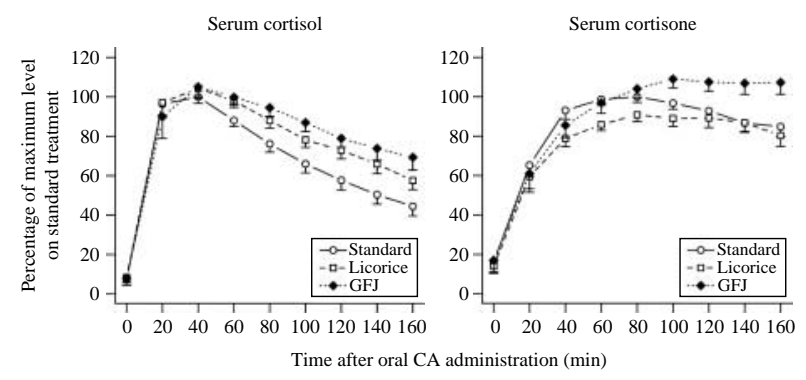

Figure 2 Time series profiles of serum cortisol (left) and cortisone (right) obtained up to $160 \mathrm{~min}$ after cortisone acetate administered orally. Responses to standard treatment and co-administration with grapefruit juice and licorice are shown separately. Hormone concentrations are normalized individually to $C_{\max }$ on standard treatment. Mean $C_{\max }$ for the whole group on standard treatment is defined as $100 \%$. Data are mean (S.E.M.). 
Table 2 Pharmacokinetics of glucocorticoid in serum and saliva. Median (range).

\begin{tabular}{cccc}
\hline & Standard treatment & Licorice co-administration & GFJ co-administration \\
\hline Serum & & & \\
Cortisol & & & \\
AUC & $50882(26032-98821)$ & $53783(39990-102034)^{\star}$ & $60661(39863-114478)^{\star}$ \\
$T_{\max }$ & $40(20-120)$ & $40(20-60)$ & $40(20-160)$ \\
$C_{\max }$ & $504(339-901)$ & $509(379-994)$ & $539(357-1040)$ \\
$C_{t=160}$ & $186(65-424)$ & $223(94-462)^{\star}$ & $337(147-666)^{\dagger}$ \\
Cortisone & & & \\
AUC & $7132(3995-10795)$ & $6375(4218-9846)^{\star}$ & $7746(5097-11675)$ \\
$T_{\max }$ & $80(30-160)$ & $80(40-140)$ & $140(20-160)^{\star}$ \\
$C_{\max }$ & $56(39-110)$ & $46(34-88)^{\dagger}$ & $61(41-98)$ \\
$C_{t=160}$ & $41(20-70)$ & $41(17-57)$ & $54(30-77)^{\dagger}$ \\
Saliva & & & \\
Cortisol & & & $1889(778-3318)^{\star}$ \\
AUC & $1267(528-4733)$ & $1683(666-4078)^{\star}$ & $40(20-160)$ \\
$T_{\max }$ & $40(20-40)$ & $40(20-60)$ & $23.3(10.0-61.8)^{\star}$ \\
$C_{\max }$ & $15.9(8.2-52.9)$ & $20.7(7.5-53.7)$ & $5.87(1.96-15.4)^{\star}$ \\
$C_{t=160}$ & $2.93(0.65-11.4)$ & $4.56(1.59-13.2)^{\star}$ & \\
Cortisone & & & $11387(6625-16799)$ \\
AUC & $9052(5611-18448)$ & $9471(4370-18156)$ & $40(20-160)^{\star}$ \\
$T_{\max }$ & $40(20-60)$ & $40(20-60)$ & $116(65.0-173)$ \\
$C_{\max }$ & $97.2(53.9-183)$ & $97.5(44.2-227)$ & $55(24.8-109)^{\dagger}$ \\
$C_{t=160}$ & $36.3(16.6-81.3)$ & $34.3(14.7-80.5)$ & \\
\hline
\end{tabular}

AUC, area under curve. Computed-time series profile after orally administered cortisone acetate; GFJ, grapefruit juice. $T_{\max }$, time of maximum concentration (min); $C_{\max }$, maximum conc. (nmol/l); $C_{t=160}$, conc. $160 \mathrm{~min}$. after oral CA administration (nmol/l). Difference from standard treatment: ${ }^{\star} P<0.05 ;{ }^{\dagger} P<0.01$.

No difference in BP was observed after GFJ intake. Body weight did not change during the study.

\section{Licorice effects}

Compared with standard treatment, serum AUC of cortisol increased by $5.7 \%(P<0.05)$ and AUC of cortisone decreased by $11 \%(P<0.05$; Fig. 2 and Table 2) with licorice. Cortisol $C_{t=160}$ in serum increased on licorice $(P<0.05$; Fig. 3$)$ and was $20 \%$ higher than on standard treatment. Salivary samples reflected the changes seen in serum for cortisol, but not for cortisone (Table 2). $C_{\max }$ and $T_{\max }$ for cortisol and cortisone were not significantly different compared with standard treatment. Plasma ACTH at $t=160$ tended to be lower than on standard treatment (median 60.1 $(1.4-194)$ vs $70.7(2.4-253) \mathrm{pmol} / \mathrm{l}, P=0.093)$. In $24 \mathrm{~h}$ urine, use of licorice increased cortisol excretion $(P<0.05$; Table 3$)$ and increased cortisol/cortisone ratio $(P<0.00001)$.

\section{GFJ effects}

For serum cortisol, AUC increased by 19\% $(P<0.05$; Fig. 2 and Table 2$)$ and $C_{t=160}$ by $81 \%$ compared with standard treatment $(P<0.01$; Fig. 3). A similar pattern was observed in saliva samples. Cortisone $C_{t=160}$ increased in serum $(P<0.01)$ and saliva $(P<0.01$; Table 2). Although there were large inter-individual differences, the median cortisone $T_{\max }$ rose from 40 to 140 min $(P<0.05)$ in serum, whereas no significant change was observed for $C_{\max }$ levels. Plasma ACTH was lower at $t=160$ compared with standard treatment (median 40.0 (1.1-167) vs 70.7 (2.4-253) pmol/l, $P<0.05)$. Intake of GFJ increased the urinary ratio $(\mathrm{aTHF}+\mathrm{THF}) / \mathrm{THE}(\mathrm{P}<0.05)$ compared with CA alone (Table 3). There was a non-significant increase in urinary cortisone excretion $(P=0.051)$.

\section{Discussion}

Conventional strategies for GC replacement in $\mathrm{AD}$ fail to mimic the physiological diurnal rhythm of cortisol. Multi-dosage regimens are usually preferred because circulating cortisol has a relatively short half-life. Unfortunately, this renders the patient both over- and under-treated during the $24 \mathrm{~h}$ cycle. To improve treatment, there has recently been considerable interest in developing slow-release or delayed-release formulations. However, the absorption and metabolism of GC may be modified by various drugs and common nutrients. In this report, we investigated the pharmacokinetic effects of GFJ and licorice on GC replacement therapy in AD. Seventeen subjects on stable CA dosages were examined with urinary steroid profiling and time series of cortisol and cortisone in serum and saliva.

Moderate intake of licorice increased the serum cortisol levels in the hours following CA administration, and cortisone levels tended to decrease. These opposite changes indicate a shift in the equilibrium between cortisol and cortisone, which largely depends on the activity of $11 \beta$-HSDs. We found that licorice co-administration increased both the urinary cortisol 


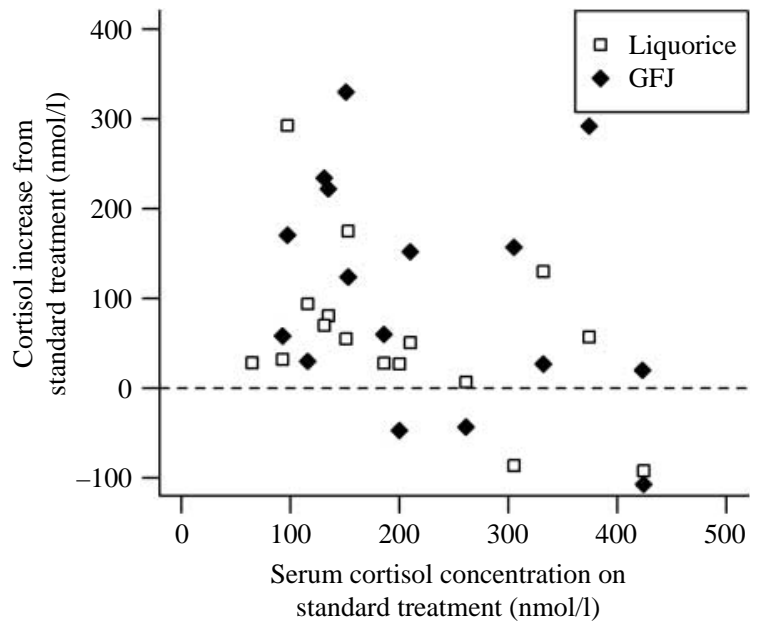

Figure 3 The impact of licorice and grapefruit juice (GFJ) on serum cortisol concentrations $160 \mathrm{~min}$ after oral administration of cortisone acetate. Cortisol concentrations on standard treatment is on the $x$-axis, while the $y$-axis shows the difference between standard treatment and treatment with GFJ and licorice co-administration.

excretion and the cortisol/cortisone ratio. This is consistent with inhibition of renal 11ß-HSD type 2 and in line with MacKenzie et al. (29) and other reports that have investigated licorice effects in healthy subjects. Interestingly, MacKenzie observed no elevation in serum cortisol, in contrast to our findings. This discrepancy is probably explained by the adrenal failure in our patients, who lack the feedback-controlled cortisol secretion that maintains serum levels within narrow limits. Accordingly, inhibition of $11 \beta$-HSD type 2 drives the equilibrium in favor of cortisol without effective counteraction.

$11 \beta$-HSD type 1 is highly expressed in the liver and also acts as pre-receptor modulator of cortisol effects in most tissues. Reports suggest that licorice inhibits $11 \beta$ HSD type $1(18,30)$, but this is not in agreement with our findings. As expected, if $11 \beta$-HSD type 1 was indeed inhibited, reduced hepatic first pass activation of $\mathrm{CA}$ would decrease cortisol $C_{\max }$ and increase $T_{\max }$. In contrast, we did not observe any changes in these pharmacokinetic parameters compared with the standard treatment. It is possible that inhibition of 11ß-HSD type 1 requires larger concentration of glycyrrhetinic acid than $11 \beta$-HSD type 2 . In the report by Armanini et al. (30), $500 \mathrm{mg}$ glycyrrhetinic acid/day was administered for 3 days, which is more than three times the dose used in our study.

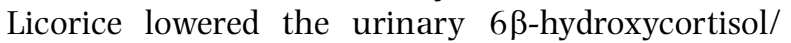
cortisol ratio, but not the total excretion of $6 \beta$-hydroxycortisol. Hence, the decreased ratio likely reflects increased urinary cortisol concentrations due to $11 \beta$ HSD type 2 inhibition, rather than inhibition of CYP3A4. The sum of all measured urinary metabolites did not change, indicating that licorice did not impact the overall absorption of $\mathrm{CA}$.

Excessive use of licorice is a known cause of pseudohyperaldosteronism due to 11ß-HSD type 2 inhibition. Surprisingly, use of licorice did not elevate $\mathrm{BP}$, but actually sitting systolic BP and 1-min standing BP decreased, even though the subjects maintained their ordinary mineralocorticoid medication. Possible explanations could be that glycyrrhetinic acid competes with fludrocortisone in access to the mineralocorticoid receptors (31), interferes with the gut absorption or metabolism of fludrocortisone, or that the intervention period of 3 days is too short to induce substantial sodium retention.

Co-administration with GFJ was even more effective than licorice in elevating circulating levels of cortisol. At the end of the time series, $2.6 \mathrm{~h}$ after oral CA, the serum level increased by $80 \%$. Steroid profiling indicated that GFJ impacts both gastrointestinal absorption and GC metabolism. When CA was taken with GFJ, the AUC increased for cortisol measured in serum and saliva compared with standard treatment. There was also an increase in AUC for cortisone, although not statistically significant. These changes strongly suggest that GFJ enhanced the gastrointestinal absorption the first $2.6 \mathrm{~h}$ after oral CA. However, the unchanged total of urinary

Table 3 Twenty-four hour urinary excretion cortisol metabolites and calculated enzyme indices. Median (range).

\begin{tabular}{|c|c|c|c|}
\hline & Standard treatment & Licorice co-administration & GFJ co-administration \\
\hline Free F & $46.6(2.00-132)$ & $61.3(7.70-281)^{\star}$ & $53.4(1.93-203)$ \\
\hline Free $\mathrm{E}$ & $180(14.9-440)$ & $166(36.1-369)$ & 200 (11.7-472) \\
\hline $6 \beta$-Hydroxycortisol & $442(7.03-968)$ & 529 (26.7-936) & $357(3.72-1740)$ \\
\hline THF & $3870(1330-7200)$ & $3710(1550-7210)$ & $3600(1490-6890)$ \\
\hline THF & $3400(1020-9650)$ & $3780(1120-9200)$ & $3658(847-7330)$ \\
\hline THE & $17400(4680-34500)$ & $17500(3870-24000)$ & $15500(5600-30400)$ \\
\hline Total metabolites & $26900(8670-47600)$ & $26600(9180-38200)$ & $26500(9850-37700)$ \\
\hline Cortisol/cortisone & $0.21(0.13-0.43)$ & $0.43(0.21-0.76)^{\ddagger}$ & $0.27(0.13-0.48)$ \\
\hline $6 \beta$-Hydroxycortisol/cortisol & 7.59 (3.54-21.8) & $5.23(3.28-12.8)^{\dagger}$ & $7.04(1.92-31.1)$ \\
\hline (aTHF + THF)/THE ratio & $0.43(0.25-0.85)$ & $0.48(0.29-1.35)$ & $0.55(0.23-1.04)^{*}$ \\
\hline aTHF/THF ratio & $0.82(0.36-2.43)$ & $0.89(0.23-2.49)$ & 0.89 (0.18-2.08) \\
\hline
\end{tabular}

GFJ, grapefruit juice; F, cortisol (nmol/24 h); E, cortisone (nmol/24 h); THF, tetrahydrocortisol (nmol/24 h); aTHF, allo-tetrahydrocortisol (nmol/24 h); THE, tetrahydrocortisone (nmol/24 h). Difference from standard treatment: ${ }^{\star} P<0.05 ;{ }^{\dagger} P<0.001 ;{ }^{\ddagger} P<0.00001$. 
cortisol metabolites is not consistent with an overall enhanced absorption during the $24 \mathrm{~h}$ cycle. Taken together, these findings indicate that GFJ co-administration gave rise to a more complete intestinal $\mathrm{CA}$ absorption during the first hours. We did not aim for detailed investigations on mechanisms that could explain differences in bioavailability. It is, however, likely that interactions between various GFJ constituents and proteins in the intestinal walls are involved. P-glycoprotein is a possible target previously linked to GFJ interactions. GFJ may also change the gut microflora, which has recently been shown to be important for the bioavailability of some orally taken compounds (32).

GFJ co-administered with CA increased cortisone $T_{\text {max }}$, albeit with considerable inter-individual differences. Some subjects had lower levels of circulating cortisone in the first 80 min compared with standard treatment but increased levels later on. This pattern suggests that GFJ delayed the onset of CA absorption. CA is unprotonated even at low $\mathrm{pH}$, which renders pH-dependent solubility and absorption less probable. A likely explanation is delayed gastric emptying due to the acidity of GFJ (33). Delayed absorption has been reported for other oral drugs taken with GFJ, for example, nifedipine (34) and methylprednisolone (35). Interestingly, even though serum $T_{\max }$ of cortisone increased, the peak concentration $\left(C_{\max }\right)$ and peak time $\left(T_{\max }\right)$ of cortisol did not change. Given that only $11 \beta$ HSD type 1 is capable of converting cortisone to cortisol, this points to enzymatic capacity as the main limiting factor for CA activation, rather than gut absorption (substrate availability). It is noteworthy that enhanced intestinal absorption does not preclude delayed gastric emptying and that both effects could occur in the same patient. It is also likely that the elevated levels of cortisol, via renal conversion by $11 \beta$-HSD type 2 , contribute to the increase in serum cortisone AUC and $T_{\text {max }}$.

GFJ increased the urinary (aTHF + THF)/THE ratio, but not cortisol/cortisone ratio. This is consistent with augmented $11 \beta$-HSD type 1 conversion of cortisone to cortisol. Only few studies on GFJ interactions with GC have been conducted with somewhat discrepant results. In a study on 12 kidney transplant patients on cyclosporine, Hollander et al. (36) found that GFJ did not alter the pharmacokinetics of prednisone and prednisolone, which are metabolized mainly by the same enzymes as cortisone and cortisol. However, Varis et al. (35) reported increased bioavailability of methylprednisolone and increased $T_{1 / 2}$ in ten subjects taking GFJ. Zhang et al. (25) found that naringenin, a flavonoid found in GFJ, inhibited both 11ß-HSD type 1 and 2 in vitro. Differences in the fruits used and in the GFJ manufacturing processes could, at least partially, account for the variable effects observed. One explanation, in line with the in vitro studies, could be that inhibition of $11 \beta$-HSD type 1 counteracted the effect of type 2 inhibition and rendered the urinary cortisol/cortisone ratio unchanged. However, this is unlikely as the serum $C_{\max }$ and $T_{\max }$ of cortisol were not impacted by GFJ intake. Gut interactions between thyroxine and GFJ are only minor (37), and probably do not influence cortisol metabolism in those treated for hypothyroidism. To our knowledge, this is the first report of a dietary component that enhances $11 \beta$-HSD type 1 activity, which is particularly interesting in view of the proposed role of this enzyme in obesity and the metabolic syndrome.

The hepatic CYP3A4 system is an acknowledged degradation pathway for cortisol (38). We found normal levels of $6 \beta$-hydroxycortisol (39) on standard treatment, which indicate that its contribution to the metabolism of cortisol is minor. However, large interindividual differences in CYP3A4 activity have been reported (39). In contrast to others, we did not find evidence of GFJ inhibition of CYP3A4; the $6 \beta$ hydroxycortisol/cortisol ratio was unchanged. One possibility is that the particular GFJ used in this study did not contain sufficient amounts of CYP3A4 inhibiting compounds.

In a recent paper, Perogamvros et al. (40) proposed salivary cortisone as the preferred biomarker for serum cortisol because it reflects its free fraction more closely than salivary cortisol. We observed a strong correlation between total serum cortisol and salivary cortisone levels, although the association to salivary cortisol was even stronger. In this study, salivary cortisol is probably the most accurate marker of free circulating cortisol, because all patients used oral CA as GC replacement. We believe that GC measurements in saliva should be cautiously interpreted in patients taking licorice. Altered activity of $11 \beta$-HSD type 2 in the salivary glands potentially interferes with measurements in oral fluids (41). In fact, inhibition of this enzyme is evident in serum and saliva cortisone levels, which changed in opposite directions during licorice intake and standard treatment. Nevertheless, it is noteworthy that not only salivary cortisol, but also cortisone levels, was considerably elevated at the end of the GFJ time series.

The impact of other doses of GFJ and licorice is difficult to extrapolate from this pilot investigation. From previous studies, we know that GFJ can cause inhibition, which lasts for days, of various enzymes by both reversible and irreversible binding (42). Some of the biological effects may plateau even at doses of $300 \mathrm{ml} /$ day. Hence, a lower GFJ dose could also have significant interactions on CA pharmacokinetics, at least in some individuals. The $24 \mathrm{~g}$ dose (one small box of tablets) of licorice is no unusual dose for the 'occasional' licorice consumer. Glycyrrhetinic acid reversibly inhibits $11 \beta$-HSD type 2 , and one would expect the effects to decrease shortly after administration has been stopped. The impact of licorice and GFJ on circulating cortisol levels raises the possibility that they may impact quality of life and risk of osteoporosis in habitual users, if CA doses are not reduced. Prospective long-term studies are needed to address this question. However, intake of licorice and GFJ 
certainly constitutes potential pitfalls when steroid levels are used to evaluate GC replacement dose adequacy $(8,9,43)$. The principle of pharmacological modification of cortisol metabolism could be a novel therapeutic option for patients with $\mathrm{AD}$ on replacement therapy. Based on data from this study, we cannot advocate that these compounds should be co-administered because long-term effects need to be established, and licorice and GFJ doses may be difficult to standardize.

We chose CA because this is the most widely used replacement drug in $\mathrm{AD}$ in our country. Additionally, the pro-hormone feature of $\mathrm{CA}$ makes this drug particularly interesting in terms of pharmacokinetic interactions. The effects of licorice co-administration would probably be comparable if $\mathrm{HC}$ was administered, because the hepatic activation of CA was not substantially inhibited. Regarding GFJ, it is likely that the acidity of this juice would delay the absorption of $\mathrm{HC}$ and $\mathrm{CA}$ similarly. As the hepatic activation efficiency of orally administered CA appears to be a main limiting factor in the time to cortisol $T_{\max }$, we speculate that the levels of circulating cortisol after HC intake may be more influenced by diet and bowel function.

A limitation of this study is that the participants and researchers were not blinded. Certainly, this would have been preferable, but the practical challenges and costs necessary to provide licorice and GFJ in concealed formulations were not justified for these pilot investigations. Due to the exploratory nature of this study, formal adjustment for multiple statistical testing was limited to the primary endpoint, i.e. AUC cortisol, in line with the recommendation of Bender \& Lange (44).

In conclusion, we show that both licorice and GFJ elevate cortisol levels in the hours following oral administration of CA in patients with primary adrenal failure. Steroid profiling indicated that licorice inhibits renal $11 \beta$-HSD type 2 , and GFJ increases hepatic $11 \beta$ HSD type 1 activity and enhances the early absorption of CA. Our findings point to the possibility of pharmacological modification of $11 \beta$-HSD activity to attenuate the fluctuations of GC levels throughout the day in patients with $\mathrm{AD}$ on replacement therapy.

\section{Declaration of interest}

The authors declare that there is no conflict of interest that could be perceived as prejudicing the impartiality of the research reported.

\section{Funding}

The study was funded by the Regional Health Authorities of Western Norway and the EU FP7 project Euradrenal (grant number 201167).

\section{Acknowledgements}

We are grateful to the Haukeland University Hospital Clinical Research Facility for their kind co-operation.

\section{References}

1 Løvås K, Loge JH \& Husebye ES. Subjective health status in Norwegian patients with Addison's disease. Clinical Endocrinology 200256 581-588. (doi:10.1046/j.1365-2265.2002.01466.x)

2 Bergthorsdottir R, Leonsson-Zachrisson M, Odén A \& Johannsson G. Premature mortality in patients with Addison's disease: a population-based study. Journal of Clinical Endocrinology and Metabolism 200691 4849-4853. (doi:10.1210/jc.20060076)

3 Crown A \& Lightman S. Why is the management of glucocorticoid deficiency still controversial: a review of the literature. Clinical Endocrinology 200563 483-492. (doi:10.1111/j.1365-2265. 2005.02320.x)

4 Simon N, Castinetti F, Ouliac F, Lesavre N, Brue T \& Oliver C. Pharmacokinetic evidence for suboptimal treatment of adrenal insufficiency with currently available hydrocortisone tablets. Clinical Pharmacokinetics $2010 \quad 49$ 455-463. (doi:10.2165/ 11531290-000000000-00000)

5 Løvås K, Gjesdal CG, Christensen $\mathrm{M}$, Wolff AB, Almås $\mathrm{B}$, Svartberg J, Fougner KJ, Syversen U, Bollerslev J, Falch JA, Hunt PJ, Chatterjee VK \& Husebye ES. Glucocorticoid replacement therapy and pharmacogenetics in Addison's disease: effects on bone. European Journal of Endocrinology 2009160 993-1002. (doi:10.1530/EJE-08-0880)

6 Wei L, MacDonald TM \& Walker BR. Taking glucocorticoids by prescription is associated with subsequent cardiovascular disease. Annals of Internal Medicine 2004141 764-770.

7 Filipsson H, Monson JP, Koltowska-Häggström M, Mattsson A \& Johannsson G. The impact of glucocorticoid replacement regimens on metabolic outcome and comorbidity in hypopituitary patients. Journal of Clinical Endocrinology and Metabolism 200691 3954-3961. (doi:10.1210/jc.2006-0524)

8 Howlett TA. An assessment of optimal hydrocortisone replacement therapy. Clinical Endocrinology 199746 263-268. (doi:10.1046/j. 1365-2265.1997.1340955.x)

9 Mah PM, Jenkins RC, Rostami-Hodjegan A, Newell-Price J, Doane A, Ibbotson V, Tucker GT \& Ross RJ. Weight-related dosing, timing and monitoring hydrocortisone replacement therapy in patients with adrenal insufficiency. Clinical Endocrinology 200461 367-375. (doi:10.1111/j.1365-2265.2004.02106.x)

10 Løvås K \& Husebye ES. Continuous subcutaneous hydrocortisone infusion in Addison's disease. European Journal of Endocrinology 2007157 109-112. (doi:10.1530/EJE-07-0052)

11 Johannsson G, Bergthorsdottir R, Nilsson AG, Lennernas H, Hedner T \& Skrtic S. Improving glucocorticoid replacement therapy using a novel modified-release hydrocortisone tablet: a pharmacokinetic study. European Journal of Endocrinology 2009 161 119-130. (doi:10.1530/EJE-09-0170)

12 Debono M, Ghobadi C, Rostami-Hodjegan A, Huatan H, Campbell MJ, Newell-Price J, Darzy K, Merke DP, Arlt W \& Ross RJ. Modified-release hydrocortisone to provide circadian cortisol profiles. Journal of Clinical Endocrinology and Metabolism 200994 1548-1554. (doi:10.1210/jc.2008-2380)

13 Groen J, Pelser H, Willebrands AF \& Kamminga CE. Extract of licorice for the treatment of Addison's disease. New England Journal of Medicine $1951 \quad \mathbf{2 4 4} \quad 471-475 . \quad$ (doi:10.1056/ NEJM195103292441303)

14 Calvert RJ. Liquorice extract in Addison's disease; successful, longterm therapy. Lancet 1954266 805-807. (doi:10.1016/S01406736(54)91476-2)

15 Cotterill JA \& Cunliffe WJ. Self-medication with liquorice in a patient with Addison's disease. Lancet 19731 294-295. (doi:10. 1016/S0140-6736(73)91541-9)

16 Cooper H, Bhattacharya B, Verma V, McCulloch AJ, Smellie WSA \& Heald AH. Liquorice and soy sauce, a life-saving concoction in a patient with Addison's disease. Annals of Clinical Biochemistry 200744 397-399. (doi:10.1258/000456307780945624)

17 Stewart PM, Murry BA \& Mason JI. Human kidney 11 betahydroxysteroid dehydrogenase is a high affinity nicotinamide 
adenine dinucleotide-dependent enzyme and differs from the cloned type I isoform. Journal of Clinical Endocrinology and Metabolism 199479 480-484. (doi:10.1210/jc.79.2.480)

18 Diederich S, Quinkler M, Burkhardt P, Grossmann C, Bähr V \& Oelkers W. 11Beta-hydroxysteroid-dehydrogenase isoforms: tissue distribution and implications for clinical medicine. European Journal of Clinical Investigation 200030 (Supplement 3) 21-27. (doi:10.1046/j.1365-2362.2000.0300s3021.x)

19 Quinkler M \& Stewart PM. Hypertension and the cortisolcortisone shuttle. Journal of Clinical Endocrinology and Metabolism 200388 2384-2392. (doi:10.1210/jc.2003-030138)

20 Seckl JR \& Walker BR. Minireview: 11beta-hydroxysteroid dehydrogenase type 1 - a tissue-specific amplifier of glucocorticoid action. Endocrinology 2001142 1371-1376. (doi:10.1210/en. 142.4.1371)

21 Alvarez AI, Real R, Pérez M, Mendoza G, Prieto JG \& Merino G. Modulation of the activity of $\mathrm{ABC}$ transporters (P-glycoprotein, MRP2, BCRP) by flavonoids and drug response. Journal of Pharmacological Sciences 201099 598-617. (doi:10.1002/jps. 21851)

22 Nowack R. Review article: cytochrome P450 enzyme, and transport protein mediated herb-drug interactions in renal transplant patients: grapefruit juice, St John's Wort - and beyond!. Nephrology 200813 337-347. (doi:10.1111/j.1440-1797.2008. 00940.x)

23 El-Sankary W, Plant NJ, Gibson GG \& Moore DJ. Regulation of the CYP3A4 gene by hydrocortisone and xenobiotics: role of the glucocorticoid and pregnane X receptors. Drug Metabolism and Disposition 200028 493-496.

24 Högler W, Wudy SA, Luef G, Hartmann MF \& Rauchenzauner M. Oxcarbazepine accelerates cortisol elimination via cytochrome P450 3A4 induction. Archives of Disease in Childhood 201095 1065. (doi:10.1136/adc.2009.167361)

25 Zhang YD, Lorenzo B \& Reidenberg MM. Inhibition of 11 betahydroxysteroid dehydrogenase obtained from guinea pig kidney by furosemide, naringenin and some other compounds. Journal of Steroid Biochemistry and Molecular Biology 199449 81-85. (doi:10.1016/0960-0760(94)90304-2)

26 Lee YS, Lorenzo BJ, Koufis T \& Reidenberg MM. Grapefruit juice and its flavonoids inhibit 11 beta-hydroxysteroid dehydrogenase. Clinical Pharmacology and Therapeutics 199659 62-71. (doi:10. 1016/S0009-9236(96)90025-9)

27 Ionita IA, Fast DM \& Akhlaghi F. Development of a sensitive and selective method for the quantitative analysis of cortisol, cortisone, prednisolone and prednisone in human plasma. Journal of Chromatography. B, Analytical Technologies in the Biomedical and Life Sciences 2009877 765-772. (doi:10.1016/j.jchromb.2009. 02.019)

28 Steen NE, Methlie P, Lorentzen S, Hope S, Barrett EA, Larsson S, Mork E, Almås B, Løvås K, Agartz I, Melle I, Berg JP \& Andreassen OA. Increased systemic cortisol metabolism in patients with schizophrenia and bipolar disorder: a mechanism for increased stress vulnerability? Journal of Clinical Psychiatry 2011. In press (doi:10.4088/JCP.10m06068yel)

29 MacKenzie MA, Hoefnagels WH, Jansen RW, Benraad TJ \& Kloppenborg PW. The influence of glycyrrhetinic acid on plasma cortisol and cortisone in healthy young volunteers. Journal of Clinical Endocrinology and Metabolism $1990 \quad 70$ 1637-1643. (doi:10.1210/jcem-70-6-1637)

30 Armanini D, Lewicka S, Pratesi C, Scali M, Zennaro MC, Zovato S, Gottardo C, Simoncini M, Spigariol A \& Zampollo V. Further studies on the mechanism of the mineralocorticoid action of licorice in humans. Journal of Endocrinological Investigation 1996 $19624-629$.
31 Armanini D, Karbowiak I \& Funder JW. Affinity of liquorice derivatives for mineralocorticoid and glucocorticoid receptors. Clinical Endocrinology 198319 609-612. (doi:10.1111/j.13652265.1983.tb00038.x)

32 Nicholson JK, Wilson ID \& Lindon JC. Pharmacometabonomics as an effector for personalized medicine. Pharmacogenomics 2010 12 103-111. (doi:10.2217/pgs.10.157)

33 Singh BN. Effects of food on clinical pharmacokinetics. Clinical Pharmacokinetics 199937 213-255. (doi:10.2165/00003088199937030-00003)

34 Odou P, Ferrari N, Barthélémy C, Brique S, Lhermitte M, Vincent A, Libersa C \& Robert H. Grapefruit juice-nifedipine interaction: possible involvement of several mechanisms. Journal of Clinical Pharmacy and Therapeutics 200530 153-158. (doi:10. $1111 /$ j.1365-2710.2004.00618.x)

35 Varis T, Kivistö KT \& Neuvonen PJ. Grapefruit juice can increase the plasma concentrations of oral methylprednisolone. European Journal of Clinical Pharmacology 200056 489-493. (doi:10.1007/ s002280000171)

36 Hollander AA, van Rooij J, Lentjes GW, Arbouw F, van Bree JB, Schoemaker RC, van Es LA, van der Woude FJ \& Cohen AF. The effect of grapefruit juice on cyclosporine and prednisone metabolism in transplant patients. Clinical Pharmacology and Therapeutics $1995 \quad 57 \quad 318-324 . \quad$ (doi:10.1016/0009-9236 (95)90157-4)

37 Greenblatt DJ. Analysis of drug interactions involving fruit beverages and organic anion-transporting polypeptides. Journal of Clinical Pharmacology 200949 1403-1407. (doi:10. 1177/0091270009342251)

38 Abel SM \& Back DJ. Cortisol metabolism in vitro - III. Inhibition of microsomal 6 beta-hydroxylase and cytosolic 4-ene-reductase. Journal of Steroid Biochemistry and Molecular Biology $1993 \mathbf{4 6}$ 827-832. (doi:10.1016/0960-0760(93)90325-Q)

39 Lutz U, Bittner N, Ufer M \& Lutz WK. Quantification of cortisol and 6 beta-hydroxycortisol in human urine by LC-MS/MS, and gender-specific evaluation of the metabolic ratio as biomarker of CYP3A activity. Journal of Chromatography. B, Analytical Technologies in the Biomedical and Life Sciences $2010 \mathbf{8 7 8}$ 97-101. (doi:10.1016/j.jchromb.2009.11.023)

40 Perogamvros I, Keevil BG, Ray DW \& Trainer PJ. Salivary cortisone is a potential biomarker for serum free cortisol. Journal of Clinical Endocrinology and Metabolism 201095 4951-4958. (doi:10. 1210/jc.2010-1215)

41 Whorwood CB, Mason JI, Ricketts ML, Howie AJ \& Stewart PM. Detection of human 11 beta-hydroxysteroid dehydrogenase isoforms using reverse-transcriptase-polymerase chain reaction and localization of the type 2 isoform to renal collecting ducts. Molecular and Cellular Endocrinology 1995110 R7-R12. (doi:10. 1016/0303-7207(95)03546-J)

42 Seden K, Dickinson L, Khoo S \& Back D. Grapefruit-drug interactions. Drugs 2010 70 2373-2407. (doi:10.2165/1158 5250-000000000-00000)

43 Peacey SR, Guo CY, Robinson AM, Price A, Giles MA, Eastell R \& Weetman AP. Glucocorticoid replacement therapy: are patients over treated and does it matter? Clinical Endocrinology $1997 \mathbf{4 6}$ 255-261. (doi:10.1046/j.1365-2265.1997.780907.x)

44 Bender R \& Lange S. Adjusting for multiple testing - when and how? Journal of Clinical Epidemiology 200154 343-349. (doi:10. 1016/S0895-4356(00)00314-0)

Received 10 June 2011

Revised version received 5 September 2011

Accepted 6 September 2011 